\title{
KINERJA KEAMANAN DAN KESELAMATAN PENERBANGAN DI MANOUVERING AREA BANDARA UDARA JUWATA TARAKAN
}

\author{
$\operatorname{Irfan}^{1}$ \\ 1Program Studi Jurusan Keselamatan Penerbangan, Akademi Teknik dan \\ Keselamatan Penerbangan \\ Jl. Salodong No. 1 Kel.Untia Kec. Biringkanaya Kota Makassar Sulawesi Selatan \\ irfanatkp@gmail.com
}

\begin{abstract}
The existence of residential areas around the Juwata Tarakan airport results in the presence of domestic residents, namely cattle entering the airport. Besides that, there is a community around the airport that crosses the runway. This condition can disrupt flight safety and security at Juwata Tarakan Airport. In addition to explaining the impact caused by the obstruction (obstruction) the purpose of this study is also to maximize air traffic services, especially the aspects of aviation security and safety. The method used in this study is a qualitative research method while some data collection techniques are interviews, documentation and observation. Techniques and data analysis using qualitative descriptive methods, namely by way of research and observations of obstruction (obstacles) that are around Juwata Tarakan Airport. The results of the study are expected that the airport management in Tarakan can provide socialization to the surrounding residents, increase security and coordination, add communication tools and make a guardrail around the airport area.
\end{abstract}

Keywords: Security, Safety

\begin{abstract}
Abstrak
Keberadaan pemukiman warga disekitar bandar udara Juwata Tarakan mengakibatkan adanya hewan peliharaan penduduk sekitar yaitu sapi yang masuk kedalam bandar udara. Disamping itu, adanya masyarakat sekitar bandar udara yang melintasi runway.Kondisi ini dapat mengganggu keamanan dan keselamatan penerbangan di Bandar Udara Juwata Tarakan.Selain menjelaskan dampak yang ditimbulkan dengan adanya obstruction (halangan) tujuan daripada penelitian ini juga adalah Memaksimalkan pelayanan lalu lintas udara utamanyaaspek keamanan dan keselamatan penerbangan. Metode yang digunakan dalam penelitian ini adalah metode penelitian kualitatif sedangkan beberapa Teknik pengambilan data yaitu wawancara, dokumentasi dan observasi. Teknik dan analisis data menggunakan metode deskriptif kualitatif yaitu dengan cara penelitian dan pengamatan tentang obstruction (halangan) yang berada disekitar Bandar Udara Juwata Tarakan. Hasil penelitian diharapkan pihak pengelolah bandara juwata Tarakan dapat memberikan sosilaisasi kepada penduduk sekitar, meningkatkan pengamanan dan koordinasi, menambah alat komunikasi serta Pembuatan pagar pembatas di sekeliling area bandar udara.
\end{abstract}

Kata kunci :Keamanan, Keselamata 


\section{PENDAHULUAN}

Sesuai Undang-Undang Republik Indonesia Nomor 1 Tahun 2009, bahwa penerbangan merupakan bagian dari sistem transportasi nasional yang mempunyai karakteristik mampu bergerak dalam waktu cepat, menggunakan teknologi tinggi, padat modal, manajemen yang andal, serta memerlukan jaminan keselamatan dan keamanan yang optimal perlu dikembangkan potensi dan peranan yang efektif dan efisien, serta membantu terciptanya pola distribusi nasional yang mantap dan dinamis.

Pesatnya perkembangan ilmu pengetahuan dan teknologi memberikan dampak yang besar terhadap dunia penerbangan. Bertambahnya jumlah masyarakat juga sangat berpengaruh terhadap perkembangan dunia penerbangan, apalagi kondisi geografis negara Indonesia yang terdiri dari banyak pulau menyebabkan pilihan transportasi yang dibutuhkan adalah sarana transportasi darat, udara dan laut. Akan tetapi, transportasi udara lebih diminati para pengguna jasa transportasi karena pertimbangan efisiensi waktu untuk sampai di tempat tujuan.

Dunia transportasi merupakan hal yang sangat penting dalam kehidupan sehari - hari dimana telah menjadi bagian yang tidak bisa terpisahkan di masyarakat. Transportasi merupakan kebutuhan mendasar bagi setiap orang yang memerlukan sarana penghubung yang efisien dalam melakukan aktivitas sehari - hari baik lewat darat, laut, maupun udara. Khusus untuk transportasi udara dimana transportasi ini menawarkan pilihan jasa transportasi yang cepat, nyaman dan efisien.

\section{LANDASAN TEORI}

Pelayanan lalu lintas udara merupakujung tombak bagi pengelola bandar udara dalam tujuannya mendukung program pemerintahan dalam bidang jasa transportasi yang secara langsung mendatangkan pendapatan bagi pemerintah. Namun bagi pemandu lalu lintas udara menciptakan pelayanan udara yang optimal seperti yang di inginkan tidaklah mudah karena dalam konteks kata optimal juga mengandung arti bahwa pelayanan tersebut juga harus safety aman), lancar, efisien dan ekonomis bagi semua kegiatan penerbangan.

Data mengenai Bandar Udara Juwata Tarakan adalah sebagai berikut :

1. Aerodrome data and physical characteristic :
a. Name of Aerodrome : Juwata
b. Location Indicator : WALR
c. Location : $3 \mathrm{Km}$ south west from Tarakan town Tarakan town
a. ARP coordinates and site at AD : $03^{\circ} 19^{\prime} 36^{\prime \prime S} 117^{\circ} 34^{\prime} 10^{\prime \prime} \mathrm{E}$
b. Elevation : 23 feet or 7,01 meters
c. MAG VAR : $0^{\circ} 33^{\prime} E(2005)$
d. True and magnetic Bearing : Rwy 06 are 056, Rwy 24 are 236
e. Runway : Runway 06 dan 24 
Tabel 1. Runway

\begin{tabular}{ccccc}
\hline $\begin{array}{c}\boldsymbol{R} W \boldsymbol{Y} \\
\begin{array}{c}\text { Designa } \\
\text { tor }\end{array}\end{array}$ & $\begin{array}{c}\text { TOD } \\
\boldsymbol{A}\end{array}$ & TORA & ASDA & LDA \\
\hline 06 & $\begin{array}{c}2250 \\
\mathrm{~m}\end{array}$ & $\begin{array}{c}2250 \\
\mathrm{~m}\end{array}$ & $\begin{array}{c}2310 \\
\mathrm{~m}\end{array}$ & $2250 \mathrm{~m}$ \\
\hline 24 & $\begin{array}{c}2250 \\
\mathrm{~m}\end{array}$ & $\begin{array}{c}2250 \\
\mathrm{~m}\end{array}$ & $\begin{array}{c}2310 \\
\mathrm{~m}\end{array}$ & $2250 \mathrm{~m}$ \\
&
\end{tabular}

Tabel 2. Taxiway

\begin{tabular}{|c|l|l|l|l|}
\hline TAXIWAY & \multicolumn{1}{|c|}{ LENGTH } & \multicolumn{1}{|c|}{ WIDTH } & \multicolumn{1}{|c|}{ STRENGTH } & SURFACE \\
\hline $\mathrm{A}$ & $90 \mathrm{M}$ & $20 \mathrm{M}$ & $46 \mathrm{FCXT}$ & ASPHALT \\
\hline $\mathrm{B}$ & $90 \mathrm{M}$ & $18 \mathrm{M}$ & $46 \mathrm{FCXT}$ & ASPHALT \\
\hline
\end{tabular}

2. Operating hours

a. Operating hours : Monday - Sunday : 23.00 - 11.00 UTC (extend and advance operation subject to airport manager approval)

b. Shift work / Duty : 23.00 - 05.00 UTC dan 05.00 - 11.00 UTC

3. Air traffic services route

Bandar Udara Juwata Tarakan selain melayani penerbangan domestik, juga melayani penerbangan internasional baik yang berjadwal maupun tidak berjadwal, berikut ini rute penerbangan di Bandar Udara Juwata Tarakan. Jalur penerbangan domestik meliputi :

a. TARAKAN - HALIM Via W 18 and W 15

b. TARAKAN - SURABAYAVia W 18 and W 31

c. TARAKAN - BALIKPAPAN Via W 18

d. TARAKAN - TANJUNG SELOR Direct R 204 TRK

e. TARAKAN - MALINAU Direct R 285 TRK

f. TARAKAN - LONG BAWAN Direct R 286 TRK

g. TARAKAN - BERAU Direct R 186 TRK

h. TARAKAN - SAMARINDA Direct R 185 TRK

i. TARAKAN - LONG APUNG Direct R 237 TRK

j. TARAKAN - NUNUKAN Direct R 006 TRK

k. TARAKAN - LONG NAWANG Direct R 239 TRK

I. TARAKAN - TOLI-TOLI Direct R 120 TRK

m. TARAKAN - MANADO Direct R 104 TRK

n. TARAKAN - PUJUNGAN Direct R 246 TRK

o. TARAKAN - LONG SULE Direct R 222 TRK

p. TARAKAN - MAHAK BARU Direct R 228 TRK 
q. TARAKAN - DATAH DIAN Direct R 241 TRK

r. TARAKAN - APAUPING Direct R 261 TRK

s. TARAKAN - TAWAU Via BAXAL A 211

4. Operator pesawat

Operator pesawat udara yang beroperasi di Bandar Udara Juwata Tarakan:

Tabel 3. Operator Pesawat

\begin{tabular}{|l|l|}
\hline \multicolumn{1}{|c|}{ SCHEDULE } & \multicolumn{1}{c|}{ UNSCHEDULE } \\
\hline LION AIR SRIWIJAYA & MAF (MISSION AVIATION \\
AIR & FELLOWSHIP) \\
BATAVIA AIR & INDONESIAN AIR FORCE (TNI-AU) \\
SUSI AIR & INDONESIAN NAVY (TNI-AL) \\
KALSTAR & INDONESIAN ARMY (TNI-AD) \\
MASWINGS & POLISI REPUBLIK INDONEISA \\
& (POLICE) \\
& CARGO RUSIA \\
& CALIBRATION FLIGHT \\
& MATHEW AIR NUSANTARA \\
& USAF \\
& FIRST RESOURCE Ltd \\
& INTAN ANGKASA AIR SERVICE \\
& WHITE SKY AIR \\
& EASTINDO AIR \\
& THAI FLYING SERVICES \\
\hline
\end{tabular}

5. Tipe pesawat yang beroperasi

Beberapa type pesawat yang sering beroperasi di Bandar Udara Juwata Tarakan :

Tabel 4. Tipe Pesawat

\begin{tabular}{|l|l|}
\hline \multicolumn{1}{|c|}{ FIXED WING } & \multicolumn{1}{|c|}{ ROTARY WING } \\
\hline B732 & BH212 \\
B733 & MIR6 \\
B739 ER & BH412 \\
C130 & MI8 \\
FK27 & MD50 \\
ATR42 & B429 \\
ATR 72 & VH1 \\
CS212 & N332 \\
C206 & \\
C208 & \\
CN235 & \\
LR23 & \\
BE28 & \\
KODIAK & \\
\hline
\end{tabular}

Bandar Udara Juwata Tarakan berada di provinsi Kalimantan Utara yang merupakan salah satu provinsi penghasil sumber daya alam yang besar khususnya bahan tambang, mineral, dan sumber daya hutan di Indonesia. Tarakan adalah kota sebagai pintu bisnis, perdagangan dan industri di Kalimantan Utara. Pelayanan 
penerbangan pada kota Tarakan di berikan oleh Bandar Udara Juwata, dengan ratarata jumlah pergerakan pesawat yang lepas landas dan pesawat yang datang mencapai 60 - 70 pergerakan per hari dan memiliki arus lalu lintas udara yang semakin padat.

Keberadaan pemukiman warga disekitar bandar udara tersebut mengakibatkan adanya hewan peliharaan penduduk sekitar yaitu sapi yang masuk kedalam bandar udara. Disamping itu, adanya masyarakat sekitar bandar udara yang melintasi runway. Kondisi ini dapat mengganggu keamanan dan keselamatan penerbangan di Bandar Udara Juwata Tarakan

\section{METODOLOGI PENELITIAN}

Penelitian ini merupakan penelitian non eksperimen dalam bentuk studi kasus terhadap pelayanan lalu lintas udara, menggunakan metode deskriptif dan kualitatif melalui dalam penelitian kualitatif diperoleh setelah melakukan grand tour observation atau grand tour question atau yang disebut dengan penjelajahan umum. Dari penjelajahan umum ini akan diperoleh gambaran umum menyeluruh yang masih pada tahap permukaan tentang situasi keamanan dan keselamatan penerbangan.

\section{Metode Pengumpulan Data}

Dalam penelitian inimenggunakan teknik pengumpulan data sebagai berikut : Wawancara, Dokumentasi, dan Observasi.

\section{Pengolahan Data}

Pengolahan data dalam penelitian ini, adalah dengan cara membandingkan data yang diperoleh dilapangan dengan persyaratan teknis atau prosedur yang berlaku terkait keamanan penerbangan.

\section{Analisis Data}

Analisis data menggunakan metode deskriptif kualitatif yaitu dengan cara penelitian dan pengamatan tentang obstruction (halangan) yang berada disekitar Bandar Udara Juwata Tarakan dan membandingkan persyaratan teknis atau prosedur yang ditetapkan pada Annex 11, Annex 14,Undang-Undang Republik Indonesia Nomor 1 Tahun 2009 tentang penerbangan serta PM 127 tentang Keamanan Penerbangan Nasional.

\section{HASIL DAN PEMBAHASAN}

Transportasi mempunyai peranan yang penting dan strategis untuk menetapkan perwujudan wawasan nusantara, memperkukuh ketahanan nasional, dan mempererat hubungan antar bangsa dalam usaha mencapai tujuan nasional. Penerbangan merupakan salah satu bidang yang sangat khusus dalam dunia transportasi. Karena penerbangan ini mempunyai karakteristik yang mampu mencapai tujuan dalam waktu cepat, mampu mengadaptasi kemajuan di masa 
depan, berteknologi tinggi dan memerlukan tingkat keselamatan tinggi. Oleh karena itu keamanan dan keselamatan penerbangan merupakan unsur yang utama dalam dunia penerbangan.

Air Traffic Control (ATC) merupakan pengatur lalu lintas udara sejak sebelum pesawat take off sampai dengan pesawat tersebut sampai ke tujuan. Sebelum pesawat take off, ATC sudah memberikan pelayanan kepada pilot yang berupa pengecekan terhadap flight plan yang diserahkan pilot kepada ATC. Flight plan berisi tentang rencana pilot dalam menerbangkan pesawat meliputi kondisi mesin pesawat, bahan bakar yang dibawa, alternative pendaratan darurat serta ketinggian dalam penerbangan. Apabila hal-hal tersebut tidak sesuai dengan ketentuan yang ada maka ATC tidak boleh mengizinkan pesawat itu untuk terbang, karena dapat mengancam keselamatan dalam penerbangan. Berdasarkan pasal 3 Bab II Undang-Undang Nomor 15 Tahun 1992 tentang Penerbangan, menyebutkan bahwa: "Tujuan penerbangan adalah untuk mewujudkan penyelenggaraan penerbangan yang selamat, aman, cepat,lancar, tertib dan teratur, nyaman dan berdaya guna, dengan biaya yang terjangkau oleh daya beli masyarakat, dengan mengutamakan dan melindungi penerbangan nasional, menunjang pemerataan, pertumbuhan dan stabilitas, sebagai pendorong, penggerak, dan penunjang pembangunan nasional serta mempererat hubungan antar bangsa". Tujuan penerbangan inilah yang menjadikan alasan mengapa dibentuk suatu lembaga pengatur lalu lintas udara yaitu Air Traffic Control (ATC) dalam dunia penerbangan

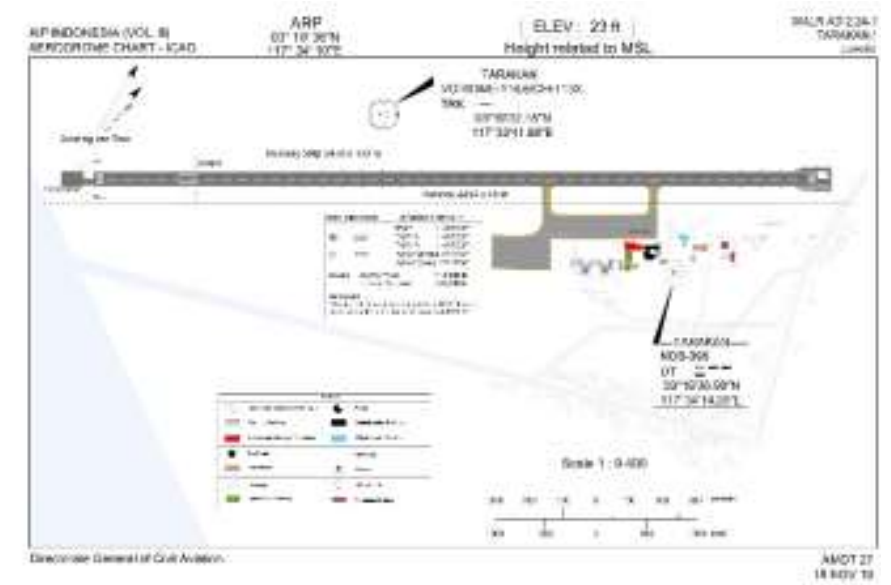

Gambar 1. AIP INDONESIA JUWATA AERODROME CHART ICAO

Melihat jumlah pergerakan traffic di Bandar Udara Juwata tarakan semakin meningkat, maka pelayanan lalu lintas udara harus pula makin ditingkatkan. Dimana permasalahan yang terjadi ialah :

Dalam pemberian pelayanan lalu lintas udara khususnya oleh Aerodrome Controller Unit harus bisa memantau semua pergerakan khususnya pada monauvering area.

Didalam Air Traffic ManagementDoc 4444 poin 7.1.1.2 "Aerodrome controllers shall maintain a continuous watch on all flight operations on and in the vicinity of an 
aerodrome as well as vehicles and personnel on the manoeuvring area. Watch shall be maintained by visual observation, augmented in low visibility conditions by an ATS surveillance system when available."

Didalam Air Traffic Management Doc. 4444 butir 7.1.1.2 disebutkan bahwa aerodrome contoller harus (shall) senantiasa memperhatikan semua kegiatan penerbangan di sekitar bandara dan di daerah pergerakan bandara dengan melalui pandangan langsung atau melalui peralatan pengawasan (surveillance system) jika tersedia.

Doc 4444 fourteenth edition chapter 7 point 7.5.3.2.2.1 (2012), All vechicles and pedestrian shall give way to aircraft which area landing, taxiing or taking off, except that emergancy vehicles proceeding to the assistance of an aircraft in distress shall be afforted priority over all other surface movement traffic. Maksudnya adalah semua kendaraan dan pejalan kaki harus memberikan jalan jika ketika pesawat mendarat, taxiing, dan lepas landas, kecuali jika pesawat yang mengalami emergency di berikan prioritas yang lebih untuk masuk ke daerah pergerakan pesawat.

Annex 14 Aerodrome volume 1 chapter 1 (2012), Aerodrome Design and Operations Fourth, Chapter I. General, 1.1 Definitions "Manoeuvring area is part of an Aerodrome to be used for take off, landing and taxiing of aircarft, excluding aprons". Jadi manoeuvring area adalah bagian dari aerodrome yang digunakan untuk take off, landing, taxiing kecuali apron

Keamanan dan keselamatan penerbangan memiliki peranan yang penting dan strategis dalam penyelenggaraan penerbangan sehingga penyelenggaraan dikuasai oleh negara dan pembinaannya, sehingga penyelenggara oleh Pemerintah dalam atau kesatuan sistem pelayanan keamanan dan keselamatan penerbangan sipil.

Hewan peliharaan dan penduduk sekitar pada maneuvering area menimbulkan masalah bagi petugas aerodrome control tower di Bandar Udara Juwata Tarakan, dalam usahanya untuk menciptakan penerbangan yang selamat, aman, lancar, tertib, teratur, nyaman, dan efisien. Dan dengan jumlah tenaga pengamanan bandar udara sebanyak 44 personil juga pembagian jam jaga pagi 9 personil dan malam 9 personil (berdasarkan data security Bandar Udara Juwata Tarakan) harus lebih di tingkatkan dan di efisienkan lagi. Setelah diamati dan dipelajari, hambatan yang menjadi bahan pengamatan disebabkan oleh :

1. Tidak adanya pagar yang membatasi daerah sekeliling Bandar Udara Juwata Tarakan.

2. Kurangnya petugas keamanan yang berpatroli untuk mengawasi pergerakan ground traffic tersebut.

3. Kurangnya koordinasi antara petugas keamanan bandara dengan petugas aerodrome control towerdi Bandar Udara Juwata Tarakan.

Kurangnya pengamanan bandara di manoeuvring area dari petugas keamanan bandara. 
Berdasarkan hasil penelitian di Bandar Udara Juwata Tarakan dapat diketahui bahwa tingkat keamanan dan keselamatan penerbangan sangat kurang. Hal ini dapat dilihat dari jumlah personel pengamanan bandara udara yang berjumlah 44 personil yang tidak memungkinkan untuk melakukan pengawasan atau patroli daerah bandar udara secara keseluruhan dengan tanpa adanya pagar pembatas di sekeliling bandar udara. Dimana ketidak adaan pagar pembatas di sekeliling bandar udara menuntut pengamanan atau pengawasan yang lebih intens. Misalnya petugas keamanan berpatroli setiap satu jam sekali agar dapat megantisipasi masuknya ground traffic ke manoeuvring area agar keamanan dan keselamatan penerbangan di Bandar Udara Juwata Tarakan dapat terwujud.

Status Bandar Udara Juwata Tarakan yaitu aerodrome control tower. Yang memberikan pelayanan pemandu lalu lintas udara kepada penerbangan baik yang menuju atau dari Tarakan termaksud juga terbang lintas (en - route) di wilayah aerodrome control tower.

Aerodrome control tower Juwata Tarakan dalam tugasnya selalu berpedoman pada peraturan penerbangan seperti yang dijelaskan pada tinjauan pustaka (BAB II), agar terwujud penerbangan yang selamat, aman, lancar, tertib, teratur, nyaman, dan efisien.

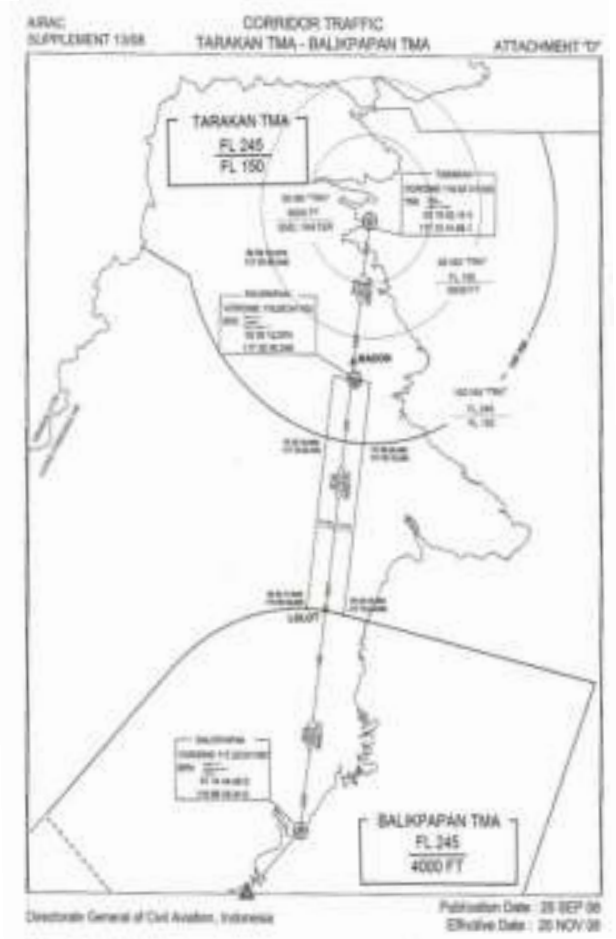

Gambar 2. CORRIDOR TRAFFIC TARAKAN TMA - BALIKPAPAN TMA

Demi menjamin keselamatan penerbangan, serta untuk menghindari hal - hal yang tidak diinginkan bagi petugas aerodrome control tower, penerbang dan pihak lain yang terkait, maka semua yang melakukan pergerakan di manoeuvring area harus mendapat ijin dari petugas aerodrome control tower. Namun pada kenyataannya 
tidak meminta ijin kepada petugas aerodrome control tower walaupun tidak ada pergerakan pesawat di ground. Meskipun demikian ini tetap membahayakan keselamatan penerbangan, karena mereka tidak mengetahui dimana posisi pesawat berada, oleh karena itu aerodrome control tower harus mengawasi lebih teliti lagi pergerakan ground traffic tersebut, dan menyampaikan kepada petugas keamanan tentang adanya ground traffic di manoeuvring area dan mengingatkan dengan menekan tombol sirine.

Petugas keamanan setelah mendapat informasi dari aerodrome control tower, baru melakukan tindakan. Ini biasanya memerlukan waktu yang lama, karena dilihat dari dari pengaturan tugas satuan pengamanan, terlihat bahwa tidak ada petugas keamanan yang khusus untuk melakukan patroli tersebut.

Beberapa masalah yang dapat ditimbulkan dari adanya ground traffic tersebut sebagai berikut

1. Pergerakan ground traffic di manoeuvring area pada saat akan mendarat dan lepas landas sangatlah berbahaya karena pesawat akan melakukan go around, dan sangat mengganggu kosentrasi penerbang yang akan sangat beresiko tinggi jika pesawat kehilangan kendali. Demikian juga pesawat akan gagal untuk lepas landas dan akan terdelay dalam beberapa menit sehingga hal ini dapat mengakibatkan ketidak lancaran lalu lintas udara.

2. Belum berjalan dengan lancar koordinasi antara petugas aerodrome control tower dengan petugas keamanan bandar udara jika ada hewan dan pejalan kaki yang melintas runway tanpa ijin.

Berdasarkan pada uraian diatas, maka penulis berpendapat bahwa adanya pergerakan ground traffic, hewan dan pejalan kaki di manoeuvring area tanpa ijin dari petugasaerodrome control tower sangat berbahaya.

Oleh karena itu penulis mencoba meninjau hubungan yang terjadi antara pergerakan ground traffic terhadap keamanan dan keselamatan penerbangan :

1. Dampak bahaya yang ditimbulkan terhadap keamanan dan keselamatan penerbangan karena adanya ground traffic.

2. Pemberian pelayanan lalu lintas udara menjadi tidak lancar dan tidak efisien karena adanya ground traffic.

3. Kurangnya koordinasi antara petugas keamanan bandara dengan aerodrome control tower jika ada ground traffic di manoeuvring area.

4. Kurangnya tingkat keamanan di manoeuvring area dari petugas keamanan bandara terhadap pergerakan ground traffic.

Memperhatikan hal tersebut maka jelas terdapat hubungan antara pergerakan ground traffic (hewan peliharaan dan penduduk sekitar) di manoeuvring area terhadap keamanan dan keselamatan penerbangan, hal ini tentunya sangat membahayakan keselamatan pernerbangan, oleh karena itu beberapa hal yang harus dilakukan oleh pihak / pengelolah bandar udara juwata tarakan diantaranya : 
1. Pemberian sosialisasi kepada masyarakat sekitar Bandar Udara tentang pentingnya keamanan dan keselamatan penerbangan terhadap pergerakan ground traffic pada manoeuvring area.

2. Meningkatkan pengamanan, koordinasi, dan peningkatan patroli dari pihak keamanan bandar udara dan antara pihak keamanan bandar udara dengan pemandu lalu lintas udara mengenai adanya ground traffic di manoeuvring area. Untuk pemberian pelayanan lalu lintas udara yang lancar dan efisien.

Menambah alat komunikasi ( handy talking) untuk berkoordinasi secara cepat antara petugas keamanan bandar udaradengan pemandu lalu lintas udara jika adanya ground traffic di manoeuvring area Bandar Udara Juwata Tarakan.

Pembuatan pagar pembatas di sekeliling area bandar udara untuk mencegah masuknya ground traffic ke dalam manoeuvring area yang dapat membahayakan keamanan dan keselamatan penerbangan.

\section{KESIMPULAN}

Kesimpulan yang diperoleh setelah melakukan pembahasan terhadap hasil yang ada adalah

1. Dampak yang ditimbulkan dengan adanya pergerakan ground traffic pada manoeuvring area, diantaranya ground traffic tersebut dapat tertabrak oleh pesawat yang akan take off dan landing, juga ground traffic tersebut dapat mengganggu kosentrasi penerbangdimana penerbang akan melakukan take offdan landing di Bandar Udara Juwata Tarakan.

2. Dengan adanya pergerakan ground traffic pada manoeuvring area akan menghambat kelancaran, ketertiban, keteraturan, kenyamanan, dan tidak efisien dalam memberikan pelayanan lalu lintas udara di Bandar Udara Juwata Tarakan.

3. Kurangnya pengamanan dari pihak keamanan bandar udara dan koordinasi antara petugas keamanan bandar udara dengan petugas lalu lintas udara.

\section{SARAN}

Saran - saran yang berkaitan dengan adanya ground traffic yang dapat membahayakan keamanan dan keselamatan penerbangan di Bandar Udara Juwata Tarakan antara lain :

1. Pemberian sosialisasi kepada masyarakat sekitar Bandar Udara tentang pentingnya keamanan dan keselamatan penerbangan terhadap pergerakan ground traffic pada manoeuvring area.

2. Meningkatkan pengamanan, koordinasi, dan peningkatan patroli dari pihak keamanan bandar udara dan antara pihak keamanan bandar udara dengan pemandu lalu lintas udara mengenai adanya ground traffic di manoeuvring area. Untuk pemberian pelayanan lalu lintas udara yang lancar dan efisien.

3. Menambah alat komunikasi (handy talking) untuk berkoordinasi secara cepat antara petugas keamanan bandar udaradengan pemandu lalu lintas udara jika adanya ground traffic di manoeuvring area Bandar Udara Juwata Tarakan. 
4. Pembuatan pagar pembatas di sekeliling area bandar udara untuk mencegah masuknya ground traffic ke dalam manoeuvring area yang dapat membahayakan keamanan dan keselamatan penerbangan.

\section{DAFTAR PUSTAKA}

Moegandi, (1993), Penerbangan Sipil, Definisi, Informasi, Istilah, dan Jargon Inggris - Indonesia, Penerbit : PT. Gramedia Pustaka Utama, Jakarta.

Martono, (2007), Kamus Hukum dan Regulasi Penerbangan Alfabet Indonesia Inggris, Jakarta, Penerbit : PT. Raja Grafindo Persada.

Zulaichah, (2012), Jurnal Perhubungan Udara Warta Ardhia; Analisis factor yang mempengaruhi kinerja personel keamanan penerbangan, Jakarta.

Makswel, T., Patar.R, Deasy.T, Jurnal Media neliti; Fungsi Pengawasan Terhadap Keselamatan Penerbangan Bandara Udara (Studi Di Bandara Udara Kuabang Kao. Kab. Halmahera Utara).

Captain. D.H, (2013) Penerbit Erlangga; Pengantar Penerbangan Perspektif Profesional, Jakarta. 